\title{
Short-Term Appraisal of the Effects and Safety of Manual Versus Ventilator Hyperinflation in an Animal Model of Severe Pneumonia
}

\author{
Gianluigi Li Bassi, Joan Daniel Martí, Talitha Comaru, Eli Aguilera-Xiol, Montserrat Rigol, \\ George Ntoumenopoulos, Silvia Terraneo, Francesca De Rosa, Mariano Rinaudo, \\ Laia Fernandez-Barat, Denise Battaglini, Andrea Meli, Miguel Ferrer, Paolo Pelosi, \\ Davide Chiumello, and Antoni Torres
}

\begin{abstract}
BACKGROUND: In patients on mechanical ventilation, lung hyperinflation is often performed to reverse atelectasis and clear retained mucus. We evaluated the effects of manual hyperinflation and ventilator hyperinflation on mucus clearance, gas exchange, pulmonary mechanics, and hemodynamics. METHODS: Six mechanically ventilated pigs with severe Pseudomonas aeruginosa pneumonia randomly received either 12 manual hyperinflation breaths over a period of 2 min (through a gradual manual compression of a resuscitation bag within $4 \mathrm{~s}$ to achieve $40 \mathrm{~cm} \mathrm{H}_{2} \mathrm{O}$ of airway pressure), or 12 ventilator hyperinflation over $2 \mathrm{~min}$ to achieve the same ventilatory end points as in manual hyperinflation. Mucus clearance rate was measured through fluoroscopic tracking of tracheal markers. Prior to each maneuver and $15 \mathrm{~min}$ thereafter, we assessed arterial and mixed gas exchange, pulmonary mechanics, and hemodynamics. RESULTS: Both manual hyperinflation and ventilator hyperinflation significantly decreased inspiratory flow by approximately $16 \mathrm{~L} / \mathrm{min}$ $(P<.001)$ and increased peak expiratory flow by roughly $44 \mathrm{~L} / \mathrm{min}(P<.001)$. The median (interquartile range) mucus clearance rate was $1.31(0.84-2.30)$ prior to the interventions, and 0.70 $(0.00-2.58)$ and $0.65(0.45-1.47)$ during manual hyperinflation and ventilator hyperinflation, respectively $(P=.09)$. Hyperinflations, whether delivered manually or through the ventilator, did not significantly modify pulmonary or hemodynamic parameters. CONCLUSIONS: In an animal model of severe $\boldsymbol{P}$. aeruginosa pneumonia, neither manual hyperinflation nor ventilator hyperinflation improved mucus clearance. If confirmed in comprehensive clinical experimentations, these findings should promote reappraisal of indications for both manual hyperinflation and ventilator hyperinflation as a therapeutic technique for mucus clearance and atelectasis reversal. Key words: mechanical ventilation; hyperinflation; mucus clearance; pneumonia; atelectasis; pulmonary mechanic. [Respir Care 2019;64(7):760-770. (C) 2019 Daedalus Enterprises]
\end{abstract}

\section{Introduction}

In critically ill patients, mechanical ventilation is a lifesaving intervention aimed at supporting ventilatory func-

Drs Li Bassi, Martí, Aguilera-Xiol, Rigol, Terraneo, De Rosa, Rinaudo, Fernandez-Barat, Ferrer, and Torres are affiliated with the Hospital Clínic, Thorax Institute, Department of Pulmonary and Critical Care Medicine, Division of Animal Experimentation, Barcelona, Spain. Drs Li Bassi, Martí, Aguilera-Xiol, Rigol, Fernandez-Barat, Ferrer, and Torres are affiliated with the Institut d'Investigacions Biomèdiques August Pi i Sunyer (IDIBAPS), Barcelona, Spain. Drs Li Bassi, Martí, Aguilera-Xiol, Fernandez-Barat, Ferrer, and Torres are affiliated with the Centro de Investigación Biomedica En Red- Enfermedades Respiratorias tion. Several iatrogenic conditions may complicate the course of mechanical ventilation, especially when patients are deeply sedated and respiratory defenses are consequently impaired. In particular, mechanically ventilated patients who are unable to breathe spontaneously, rapidly

(CIBERES), Barcelona, Spain. Drs Li Bassi, Ferrer, and Torres are affiliated with the University of Barcelona, Barcelona, Spain. Dr Comaru is affiliated with the Instituto Federal Farroupilha/Campus Santo Ângelo, Santa Maria, Brazil. Dr Rigol is affiliated with the Hospital Clínic, Thorax Institute, Cardiology Department, Barcelona, Spain. Dr Ntoumenopoulos is affiliated with the Physiotherapy Department, Guy's \& St Thomas' NHS Foundation Trust, United Kingdom, and the Physiotherapy 
develop atelectasis, leading to ventilation perfusion mismatch and impaired gas exchange. ${ }^{1,2}$ Moreover, following tracheal intubation, the mucociliary escalator is drastically weakened ${ }^{3}$ and mucus is chronically retained. Indeed, Konrad et $\mathrm{al}^{4}$ demonstrated in ICU subjects a 10 -fold decrease

See the Related Editorial on Page 870

in mucociliary clearance rate, as well as higher risks of developing pulmonary infections. Mechanical ventilation has been found to induce a paradoxical displacement of mucus toward the main bronchi in animal models, ${ }^{5-8}$ which is thought to be driven by gravity and the inspiratory flow.

In operating rooms and ICUs, lung hyperinflation is a technique commonly performed to reverse pulmonary atelectasis and clear retained mucus. ${ }^{9}$ This could be achieved manually through a resuscitating bag, namely manual hyperinflation, ${ }^{10}$ or by modifying the ventilatory settings (ie, ventilator hyperinflation). ${ }^{11}$ During manual hyperinflation, the patient is disconnected from the ventilator and a slow inspiration of a larger tidal volume $\left(\mathrm{V}_{\mathrm{T}}\right)$ is delivered via a resuscitation bag. Then, after an inspiratory pause, the operator releases the inflation bag to ensure a rapid increase in the expiratory flow. Manual hyperinflation presents some inherent risks due to the disconnection from the mechanical ventilator and the marginal control of the amplitude and duration of the lung inflation, which may vary based on the operator's level of training and the loss of PEEP. ${ }^{12}$ Ventilator hyperinflation is a suitable alternative to avoid such adverse effects. ${ }^{13}$

\footnotetext{
Services Critical Care, St Vincent's Hospital Sydney, Sydney, Australia. Drs Battaglini and Pelosi are affiliated with the Dipartimento Scienze Chirurgiche e Diagnostiche Integrate (DISC), Università degli Studi di Genova, Genova, Italia. Drs Meli and Chiumello are affiliated with the Dipartimento di Anestesia e Rianimazione, ASST Santi Paolo e Carlo, Dipartimento di Scienza e Salute - Universita degli Studi di Milano, Milan, Italy.
}

Drs Li Bassi and Martí are co-first authors.

The authors have reported relationships with Institut d'Investigacions Biomèdiques August Pi i Sunyer (IDIBAPS), Ministerio de Ciencia e Innovación (PS09/01249); Fundació Catalana de Pneumologia (FUCAP); Sociedad Española de Neumología y Cirugía Torácica (SEPAR); Centro de Investigación Biomedica En Red-Enfermedades Respiratorias (CIBERES).

Dr Li Bassi presented a version of this paper at the 26th ESICM Meeting, held October 5-9, 2013, in Paris, France.

Correspondence: Antoni Torres MD PhD, Pulmonary and Critical Care Unit Hospital Clínic, Calle Villarroel 170, Esc 6/8 Planta 208036 Barcelona, Spain. E-mail: atorres@ clinic.ub.es.

DOI: $10.4187 /$ respcare. 06487

\section{QUICK LOOK}

\section{Current knowledge}

During invasive mechanical ventilation, lung hyperinflation is one of the most common ventilatory techniques performed to reverse atelectasis and clear retained mucus. Ventilator hyperinflation is a suitable alternative, but studies providing a detailed comparison of the effects of both techniques on mucus clearance are lacking.

\section{What this paper contributes to our knowledge}

Our findings in an animal model of severe pneumonia corroborate that neither manual nor ventilator hyperinflation significantly improved mucus clearance. Furthermore, both interventions affected gas exchange and hemodynamic parameters similarly.

To our knowledge, 4 clinical studies have compared the effects of manual hyperinflation and ventilator hyperinflation and found no differences in sputum wet weight, dynamic and static pulmonary compliance, oxygenation, and hemodynamic stability. ${ }^{14}$ These reports were limited by the use of surrogate outcomes to estimate the effectiveness of the techniques on mucus clearance. Based on these previous results, we hypothesized that manual hyperinflation and ventilator hyperinflation could have comparable benefits through the improvement of mucus clearance. Therefore, we designed this laboratory study in pigs with severe bilateral pneumonia to comprehensively evaluate efficacy and safety of manual hyperinflation and ventilator hyperinflation. In particular, we aimed to compare the effect of manual hyperinflation and ventilator hyperinflation on mucus clearance rate. We also evaluated the effects on pulmonary mechanics, gas exchange, and hemodynamics.

\section{Methods}

This study was conducted at the Animal Research Laboratories of the University of Barcelona, Spain. Animals were managed according to local Spanish regulations for the care and use of laboratory animals. The protocol was carried out in pigs with severe Pseudomonas aeruginosa pneumonia, enrolled into a concomitant 76-h study to assess new strategies for endotoxin clearance. ${ }^{15}$

\section{Animal Preparation and Management}

Six female Large White-Landrace pigs $(32.8 \pm 3.1 \mathrm{~kg}$; range, 30-34 kg) were orotracheally intubated with a 7.5-mm inner diameter Hi-Lo endotracheal tube (Mallinck- 
rodt Medical, Athlone, Ireland) and placed on mechanical ventilation (Servo-i, Maquet, Bridgewater, New Jersey) initially set as follows: volume-control mode, $\mathrm{V}_{\mathrm{T}} 10 \mathrm{~mL} / \mathrm{kg}$, respiratory rate 15-20 breaths/min, PEEP $3 \mathrm{~cm} \mathrm{H}_{2} \mathrm{O}$, and $\mathrm{F}_{\mathrm{IO}_{2}}=0.4$. Ventilatory settings were adjusted throughout the experiment to maintain $\mathrm{P}_{\mathrm{aO}_{2}} \geq 95 \mathrm{~mm} \mathrm{Hg}, \mathrm{P}_{\mathrm{aCO}_{2}}=35-$ $45 \mathrm{~mm} \mathrm{Hg}$, and plateau airways pressure $\leq 25 \mathrm{~cm} \mathrm{H}_{2} \mathrm{O}$. A heated humidifier was set to maintain the airway temperature proximal to the Y-piece at $37^{\circ} \mathrm{C}$, and the inspiratory line was fully thermo-insulated with foam rubber. During surgical preparation, and throughout the study, anesthesia was maintained with a continuous infusion of midazolam and fentanyl. ${ }^{5}$ Ultrasound-guided femoral artery cannulation was performed for systemic arterial pressure monitoring and collection of blood samples. We inserted a 7-Fr balloontipped Swan-Ganz catheter into the right jugular vein for hemodynamic monitoring and sampling of blood for mixed venous gas exchange. All pigs received continuous intravenous infusion of fluids to maintain fluid balance.

\section{Model of Severe P. Aeruginosa Pneumonia}

Following surgical preparation and hemodynamic stabilization, bronchoscopic-guided pulmonary inoculation of $75 \mathrm{~mL} 10^{8}$ colony-forming units of pathogenic ceftriaxone-resistant $P$. aeruginosa was performed, as previously reported. ${ }^{16}$ After $24 \mathrm{~h}$, pneumonia was confirmed as $\mathrm{P}_{\mathrm{aO}_{2}} / \mathrm{F}_{\mathrm{IO}_{2}}$ dropped to $<100$ and the pigs exhibited at least 2 of the following clinical signs: purulent secretions, fever, or leukocytosis.

\section{Randomization}

At $24 \mathrm{~h}$ after the bacterial challenge, the animals were randomized to receive either manual hyperinflation or ventilator hyperinflation. Then, at $48 \mathrm{~h}$ after the bacterial challenge, the other intervention was applied. One hour prior to the procedure, tracheal secretions were aspirated. The animals were positioned prone, with the bed fully horizontal, approximately $15 \mathrm{~min}$ prior to the commencement of the protocol and kept in this position for the duration of the interventions. The internal endotracheal tube cuff pressure was set at $40 \mathrm{~cm} \mathrm{H}_{2} \mathrm{O}$ to prevent air leakage during the procedure, and rates of sedatives and analgesics were increased by $20 \%$ to ensure absence of spontaneous ventilation and cough reflex.

Manual Hyperinflation. Pigs were disconnected from the mechanical ventilator, and a self-inflating 1.5 -L resuscitation bag (Mark IV Adulto, AMBU, Germany) was connected to the tip of the endotracheal tube. An in-line fresh $\mathrm{O}_{2}$ flow of $15 \mathrm{~L} / \mathrm{min}$ was delivered. A PEEP valve (Intersurgical, Wokingham, United Kingdom) was connected to the resuscitation bag and adjusted to the level set at the ventilator before disconnection. A gradual two-handed compression of the resuscitation bag was performed every second, until airway pressure reached, within $4 \mathrm{~s}, 40 \mathrm{~cm} \mathrm{H}_{2} \mathrm{O}$ (Fig. 1A). An in-line pressure manometer was used to monitor the maneuver. This was followed by an inspiratory hold, and a rapid release of the bag to generate an expiratory flow-bias. Twelve hyperinflations ( 6 breaths/min) were delivered during $2 \mathrm{~min}$, with inspiratory and expiratory time of $4 \mathrm{~s}$ and $2 \mathrm{~s}$ of inspiratory pause per each breath. Manual hyperinflations were always performed by the same operator (GLB), who has $>10$ years of experience in pulmonary management of critically ill patients.

Ventilator Hyperinflation. Ventilatory settings were adjusted to achieve 12 lung hyperinflations for $2 \mathrm{~min}$ (ie, respiratory rate of 6 breaths/min), as during manual hyperinflation. $\mathrm{V}_{\mathrm{T}}$ was augmented until airway pressure reached $40 \mathrm{~cm} \mathrm{H}_{2} \mathrm{O}, \mathrm{F}_{\mathrm{IO}_{2}}$ increased to 1.0 , and the inspiratory-expiratory ratio was set to $1.5: 1$. Inspiratory rise time and inspiratory pause time were set at $0 \mathrm{~s}$ and $2 \mathrm{~s}$, respectively, to achieve an inspiratory and expiratory time of $4 \mathrm{~s}$ and an inspiratory pause of $2 \mathrm{~s}$ (Fig. 1). PEEP was maintained accordingly to the previous level on mechanical ventilation.

\section{Gas Exchange, Pulmonary Mechanics, and Hemodynamics}

Prior to the maneuver and $15 \mathrm{~min}$ thereafter, we assessed arterial and mixed gas exchange, pulmonary mechanics, and hemodynamics. As detailed in previous reports, ${ }^{5}$ we recorded flows, airway pressures, and esophageal pressures; we computed respiratory system, lung, and chest wall elastances, as well as respiratory system, flow, and pulmonary tissue resistances. We also monitored mean arterial pressure, pulmonary artery pressure, central venous pressure, pulmonary artery wedge pressure, and cardiac output. We computed stroke volume, systemic vascular resistance, pulmonary vascular resistance, venous admixture, and oxygen extraction ratio. ${ }^{5}$

Flows, airway pressures, and esophageal pressures were also continuously recorded during the maneuvers. Thus, we analyzed flow and pressure waveforms of every other breath (6 hyperinflations) and computed the $\mathrm{V}_{\mathrm{T}}$, the mean inspiratory flow, the peak expiratory flow (PEF), and the mean expiratory flow from the beginning of expiration to zero-flow. Biases between PEF and mean inspiratory flow and between mean expiratory flow from the beginning of expiration to zero-flow and mean inspiratory flow biases were also calculated as previously described. ${ }^{5}$ These replicated assessments (6 values) were averaged for the final analysis. 

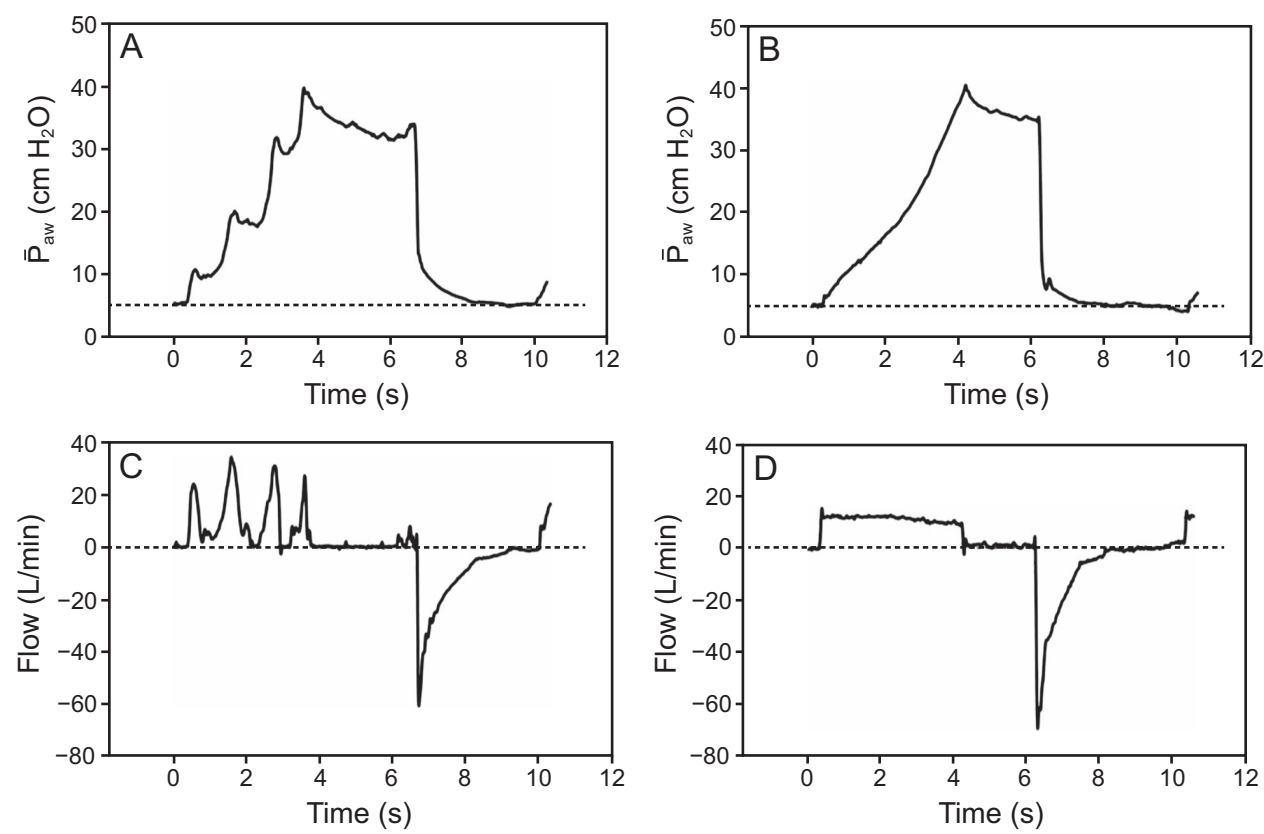

Fig. 1. Airway pressures and flows during manual $(A, C)$ and ventilator $(B, D)$ hyperinflations. Upon manual hyperinflation, a gradual compression of the resuscitation bag was performed every second until airway pressure reached $40 \mathrm{~cm} \mathrm{H}_{2} \mathrm{O}$ within $4 \mathrm{~s}$. This was followed by an inspiratory pause of $2 \mathrm{~s}$ and a rapid release of the bag to facilitate a high expiratory flow. During ventilatory hyperinflation, tidal volume was augmented until airway pressure reached approximately $40 \mathrm{~cm} \mathrm{H}_{2} \mathrm{O}$. Inspiratory rise time and inspiratory pause time were set at $0 \mathrm{~s}$ and $2 \mathrm{~s}$, respectively, to achieve an inspiratory and expiratory time of $4 \mathrm{~s}$ and an inspiratory pause of $2 \mathrm{~s}$. Of note, in both maneuvers, PEEP was maintained accordingly to the previous level on mechanical ventilation. $\overline{\mathrm{P}}_{\mathrm{aw}}=$ mean airway pressure.

\section{Assessment of Mucus Clearance}

Mucus Clearance Rate. At baseline, we measured tracheal mucus velocity for 10 min via radiographic tracking of radio-opaque disks placed into the trachea and sequential fluoroscopic images taken every 2 min, as previously reported. ${ }^{5}$ Furthermore, we took 2 fluoroscopic images, one prior to and one upon completion of the interventions, to measure the effects of hyperinflations on tracheal mucus velocity. Only disc movement in the most dependent (ie, ventral) surface were included into the analysis. For each intervention, disk movements were averaged. Mucus rates were characterized by a positive or negative vector when moving toward the glottis or the main bronchi, respectively.

Collected Secretions. At the end of the maneuvers, tracheal suctioning was performed, and secretions were collected through a 10-Fr suctioning catheter with mucous trap (Argyle Suction Catheter with Mucus Trap, Covidien, Mansfield, Massachusetts). At the end of the suctioning procedure, we squeezed the entire length of the catheter to obtain the remaining mucus adherent to the internal surface. Finally, mucus was aspirated from the mucus trap through a 5-mL syringe. We measured and recorded the wet weight and volume of collected secretions.

\section{Statistical Analysis}

Based on the results of our previous studies, 5,6 we assumed a typical mean mucus clearance rate of $8 \mathrm{~mm} / \mathrm{min}$ in animals in the prone horizontal position. In the lung hyperinflation groups, we assumed a 2 -fold increase in mucus clearance rate. A standard deviation of $2 \mathrm{~mm} / \mathrm{min}$ per each group was expected. Thus, we calculated that approximately 6 animals should be included to detect statistically significant differences between the sequential interventions, for a statistical power of $80 \%$ and type 1 bias of $5 \%$. Values are reported as mean \pm SD or median (interquartile range). Mucus clearance analysis and comparisons of variables collected before, during, and after interventions were performed using a restricted maximum likelihood analysis, based on a repeated measures approach and including the effects of the interventions, times of assessment, and their interactions and day of assessment as additional covariates. A compound symmetry or heterogeneous autoregressive covariance structure was applied. Post hoc comparisons were adjusted using Bonferroni correction. Categorical variables were analyzed using Fisher exact test. All tests were performed 2-sided with a significance level of 5\%. Analyses were performed using SAS software (version 9.2; SAS Institute, Cary, North Carolina). 

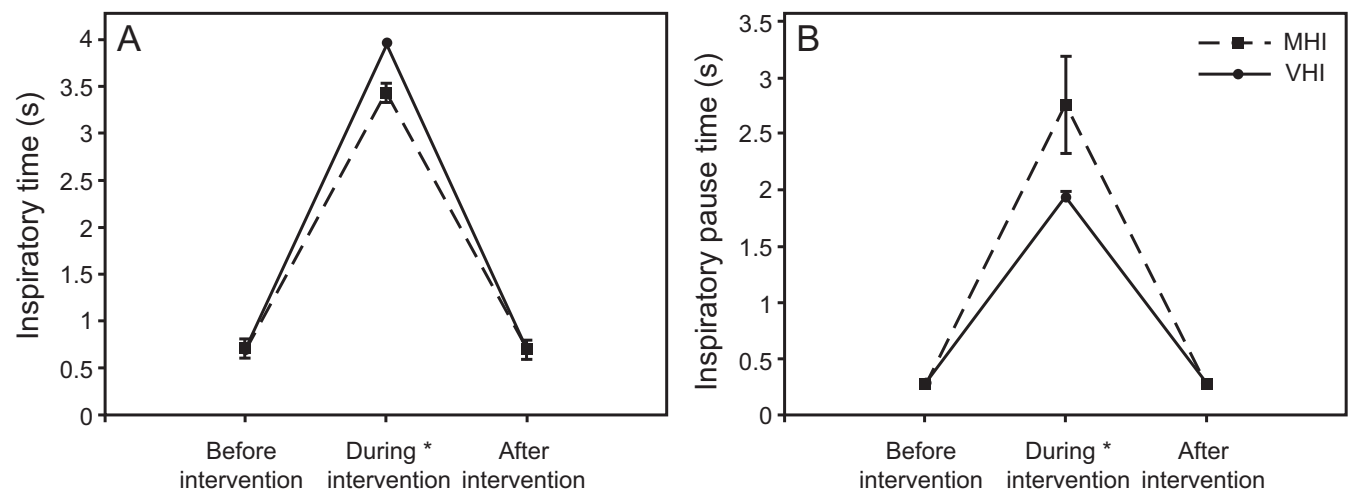

Fig. 2. Inspiratory time and inspiratory pause during ventilator and manual hyperinflations. Data are reported as mean and standard deviation. A: As expected, type of intervention and time of assessment modified the inspiratory time, without differences between days of assessment $(P=.48)$. B: Similarly, for both interventions, times of assessment and the days of assessment $(P=.03)$ modified the inspiratory pause time. ${ }^{*}$ Post-hoc analysis of effect time of assessment $(P<.001)$ vs. before and after treatment. MHI = manual hyperinflation; $\mathrm{VHI}=$ ventilator hyperinflation.

\section{Results}

All animals completed the study. At $24 \mathrm{~h}$ after bacterial inoculation, pneumonia was confirmed in all animals with the following indications: $\mathrm{P}_{\mathrm{aO}_{2}} / \mathrm{F}_{\mathrm{IO}_{2}}$ decreased by $153.3 \pm 73.2 \mathrm{~mm} \mathrm{Hg}(P=.01)$; purulent respiratory secretions were present in all animals; temperature increased from $36.8 \pm 1.1$ to $39.0 \pm 0.8^{\circ} \mathrm{C}(P=.001)$; and white blood cells increased from $13.0 \pm 3.9$ to $17.5 \pm 8.0$ cells $/ \mathrm{mm}^{3}(P=.050)$.

\section{Manual Hyperinflation and Ventilator Hyperinflation Features}

As depicted in Figure 2, interventions prolonged the inspiratory time $(P<.001)$, more so with ventilator hyperinflation $(P<.001$ vs manual hyperinflation). Similarly, the inspiratory pause time was increased by both interventions $(P<.001)$, more so with manual hyperinflation $\left(P<.001\right.$ vs ventilator hyperinflation). $\mathrm{V}_{\mathrm{T}}$ during manual hyperinflation and ventilator hyperinflation increased from $314.0 \pm 24.1 \mathrm{~mL}$ to $656.6 \pm 150.3 \mathrm{~mL}$ and from $327.5 \pm 32.2 \mathrm{~mL}$ to $838.3 \pm 75.1 \mathrm{~mL}(P<.001)$, respectively, without significant differences between interventions $(P=.18)$ or days of assessment $(P=.32)$. Delivered $\mathrm{V}_{\mathrm{T}}$ was highly variable during manual hyperinflation, but it was consistently delivered by ventilator hyperinflation (Fig. 3). Mean \pm SD peak inspiratory pressure was not different between interventions $(P=.07)$ or days of assessment $(P=.61)$, but it did differ among times of assessment $(P<.001), 24.1 \pm 3.1,38.2 \pm 0.6$, and $26.9 \pm 5.5 \mathrm{~cm} \mathrm{H}_{2} \mathrm{O}$, respectively, during manual hyperinflation; whereas, during ventilator hyperinflation it was $24.3 \pm 3.3,40.3 \pm 1.2$, and $24 \pm 3.8 \mathrm{~cm} \mathrm{H}_{2} \mathrm{O}$. Figure 4 details air flows during the interventions; Figure 5 depicts air flow biases. Both manual hyperinflation and ventilator hyperinflation significantly decreased mean inspiratory flow by approximately $16 \mathrm{~L} / \mathrm{min}(P<.001$ vs before and after interventions) and increased PEF by roughly $44 \mathrm{~L} / \mathrm{min}(P<.001$ vs before and after interventions). As a result, the bias between PEF and mean inspiratory flow increased by $60 \mathrm{~L} / \mathrm{min}$ during both interventions $(P<.001$ vs before and after interventions). Mean expiratory flow from the beginning of expiration to zeroflow increased by approximately $1.5 \mathrm{~L} / \mathrm{min}$ and $5.5 \mathrm{~L} / \mathrm{min}$ during manual hyperinflation and ventilator hyperinflation, respectively, resulting in substantial increases in the bias between mean expiratory flow from the beginning of expiration to zero-flow and mean inspiratory flow of around $16 \mathrm{~L} / \mathrm{min}$ and $21 \mathrm{~L} / \mathrm{min}$ for manual hyperinflation and ventilator hyperinflation, respectively $(P<.001$ vs before and after interventions).

\section{Effects of Manual Hyperinflation and Ventilator Hyperinflation on Mucus Clearance}

A total of 158 movements of discs on the most dependent tracheal regions were averaged and included in the final analysis. Figure 6 depicts the results of mucus clearance studies per intervention and day of assessment. $\mathrm{Mu}-$ cus moved toward the glottis during baseline assessments, and it was decreased by manual hyperinflation and ventilator hyperinflation but did not reach significance $(P=.09)$. Mucus moved toward the main bronchi in $20 \%$ and $16.7 \%$ of manual hyperinflation and ventilator hyperinflation interventions, respectively, and never during baseline assessments $(P=.73)$. Furthermore, retrieved mucus volume was $0.7 \pm 0.4 \mathrm{~mL}$ in manual hyperinflation and $0.3 \pm 0.2 \mathrm{~mL}$ in ventilator hyperinflation $(P=.69)$, which weighed $888.5 \pm 563.8 \mathrm{mg}$ in the manual hyperinflation group and $528.8 \pm 356.7 \mathrm{mg}$ in the ventilator hyperinflation group $(P=.64)$. Finally, mucus volume was 


\section{Manual vs Ventilator Hyperinflation in an Animal Model}
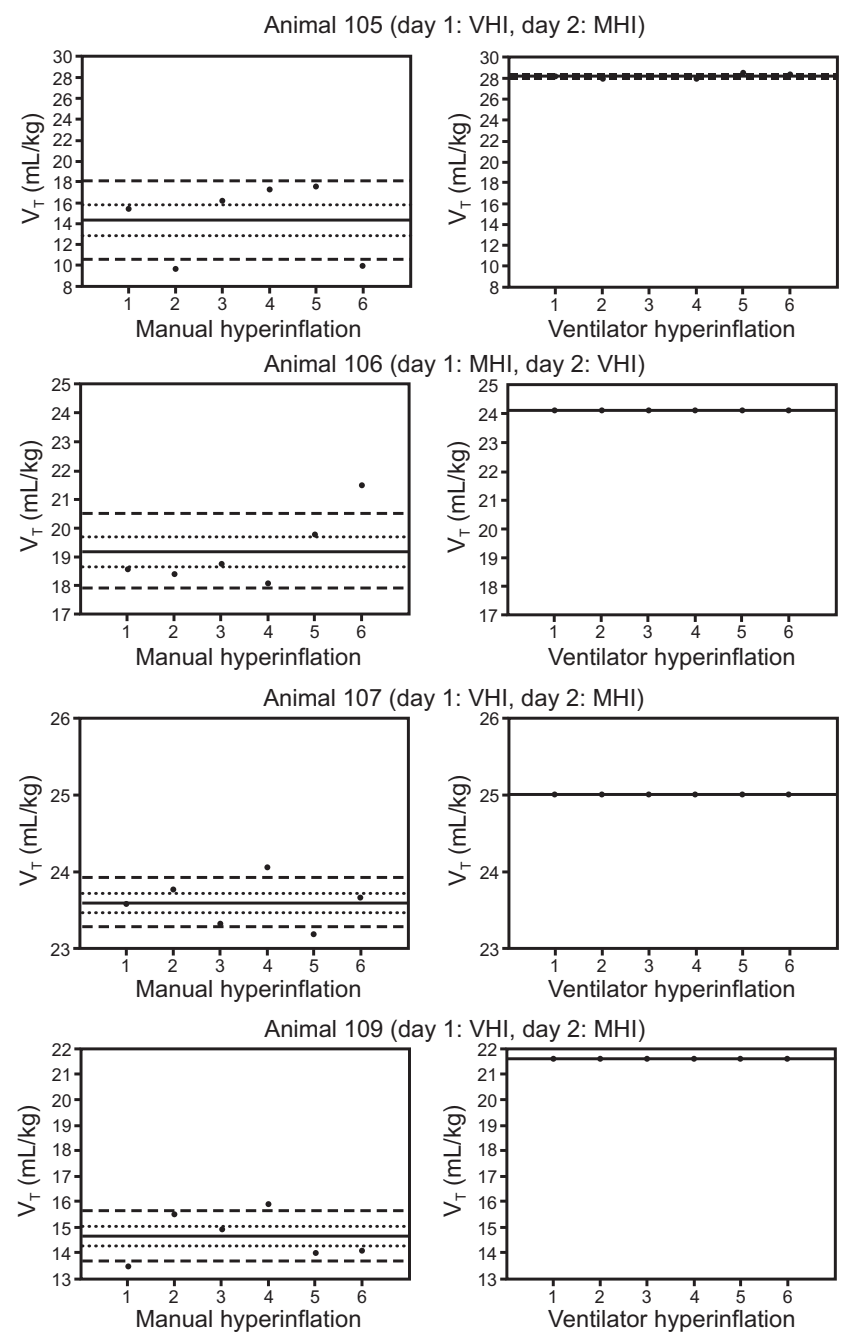

Animal 111 (day 1: MHI, day 2: VHI)

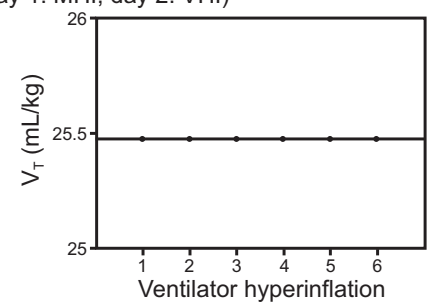

Animal 112 (day 1: MHI, day 2: VHI)
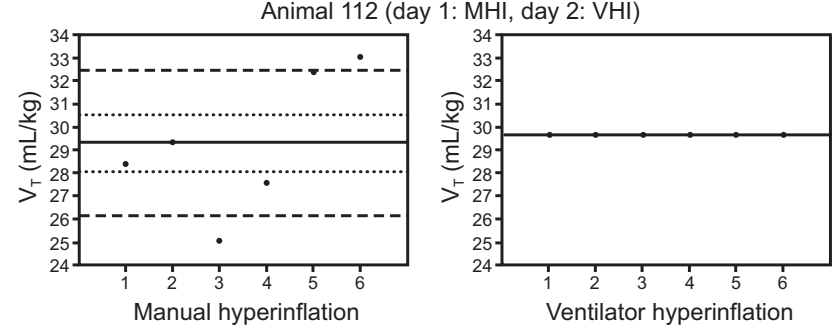

Fig. 3. $V_{\mathrm{T}}(\mathrm{mL} / \mathrm{kg})$ delivered during manual hyperinflation (left) and ventilator hyperinflation (right) per each animal. The solid lines depict the average of the 6 assessments; the upper and lower dotted lines indicate the standard error, and dashed lines indicate $95 \% \mathrm{Cl}$. Recorded data of animal 111 were not available to compute $V_{T}$ delivered manually. On average, $V_{T}$ during manual hyperinflation was $20.2 \pm 6.1 \mathrm{~mL} / \mathrm{kg}$, whereas $\mathrm{V}_{\mathrm{T}}$ during ventilator hyperinflation was $25.6 \pm 2.7 \mathrm{~mL} / \mathrm{kg}(P<.001)$. Of note, the hyperinflations manually delivered were highly variable. Conversely, the hyperinflations during ventilator hyperinflation were consistent. $\mathrm{MHI}=$ manual hyperinflation; $\mathrm{VHI}=$ ventilator hyperinflation; $\mathrm{V}_{\mathrm{T}}=$ tidal volume. 

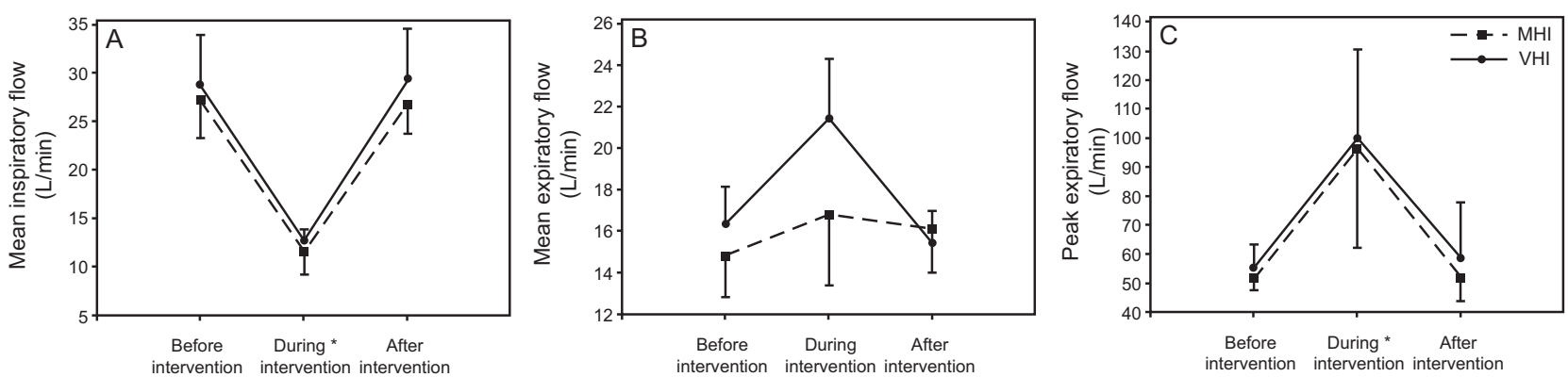

Fig. 4. Flows generated before, during, and after either manual or ventilator hyperinflation. Data are reported as mean \pm SD. A: Mean inspiratory flow did not differ between interventions or days of assessment $(P=.82)$ but differed among times of assessment. B: Mean expiratory flow differed among times of assessment. C: Peak expiratory flow did not vary between interventions $(P=.63)$ or days of assessment $(P=.95)$, but they differed among times of assessment $(P<.001){ }^{*}$ Post-hoc analysis $P<.001$ vs. before and after treatment. $\mathrm{MHI}=$ manual hyperinflation; $\mathrm{VHI}=$ ventilator hyperinflation.
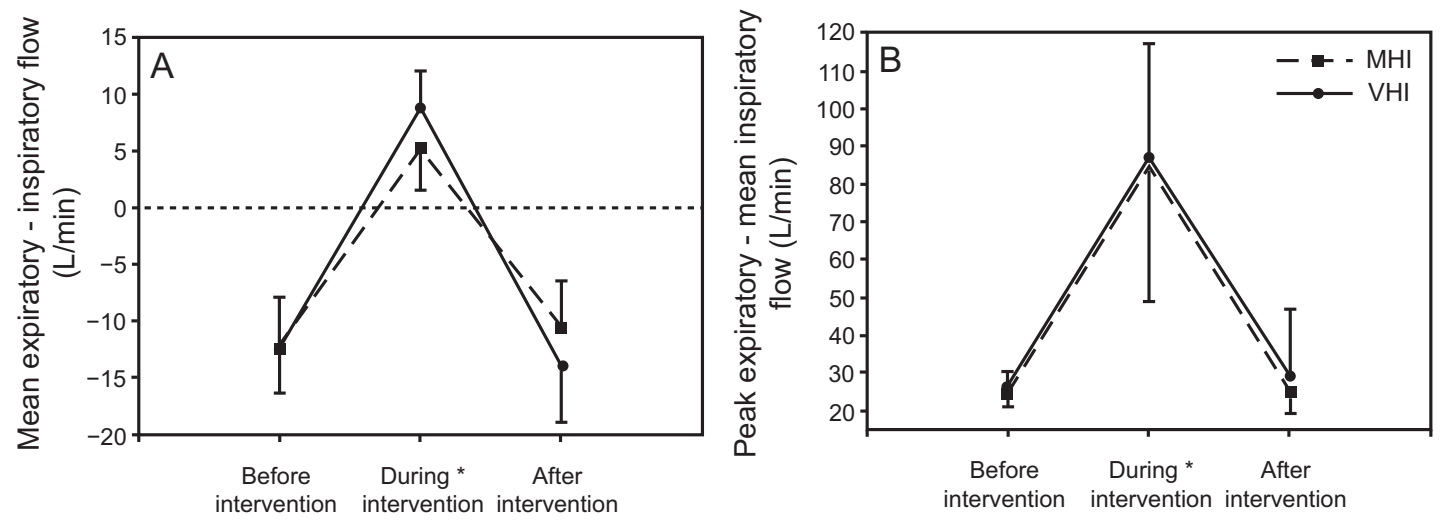

Fig. 5. Flow biases generated before, during, and after either manual or ventilator hyperinflation. Data are reported as mean \pm SD. A: Bias between mean expiratory flow and inspiratory flow did not differ among interventions or days of assessment $(P=.63)$, but there was significant difference among times of assessments. Of note, the manual and ventilator hyperinflations reversed the negative expiratory flow bias. B: The bias between peak expiratory flow and mean inspiratory flow differed among interventions and times of assessment, but without variations between days $(P=.97)$. *Post-hoc analysis $P<.001$ vs. before and after treatment. $\mathrm{MHI}=$ manual hyperinflation; $\mathrm{VHI}=$ ventilator hyperinflation.

$0.5 \pm 0.3 \mathrm{~mL}$ during the first day of assessment and $0.6 \pm 0.5 \mathrm{~mL}$ during the second day $(P=.99)$, and the respective weights were $637.5 \pm 344.0 \mathrm{mg}$ and $779.8 \pm 626.3 \mathrm{mg}(P=.84)$.

\section{Effects of Manual Hyperinflation and Ventilator Hyperinflation on Gas Exchange, Pulmonary Mechanics, and Hemodynamics}

Interventions similarly increased heart rate $(P<.001)$. median (interquartile range) heart rate measurements before, during, and after interventions were 61 (54-73), 72 (62-119), and 73 (67-119) beats/min with manual hyperinflation, respectively; with ventilator hyperinflation, the respective heart rate measurements were $67(51-79), 80$ (69-101), and 83 (64101) beats/min. Conversely, interventions did not affect mean (range) arterial pressures $(P=.54)$, which were 76.5 (7687), 83 (78-91), and 87.5 (80-96) $\mathrm{mm} \mathrm{Hg}$ before, during, and after manual hyperinflation, respectively, and 85.5 (80-
86), 90.5 (81-96), and 80 (76-86) $\mathrm{mm} \mathrm{Hg}$, respectively, with ventilator hyperinflation. As reported in Table 1, pulmonary mechanics and hemodynamics changed over time, but manual hyperinflation and ventilator hyperinflation affected these parameters analogously.

\section{Discussion}

The results of this study indicate that manual hyperinflation and ventilator hyperinflation have similar marginal effects on mucus clearance in an animal model with severe $P$. aeruginosa pneumonia. In addition, both interventions improved expiratory flow bias, and ventilator hyperinflation results in more consistent delivery of lung hyperinflation.

To date, clinical evidence on the effects of manual hyperinflation or ventilator hyperinflation is scant, inconclusive, and lacks objective outcomes to assess the benefits of the interventions. Taking these limitations into account, in several studies manual hyperinflation produced short-term 

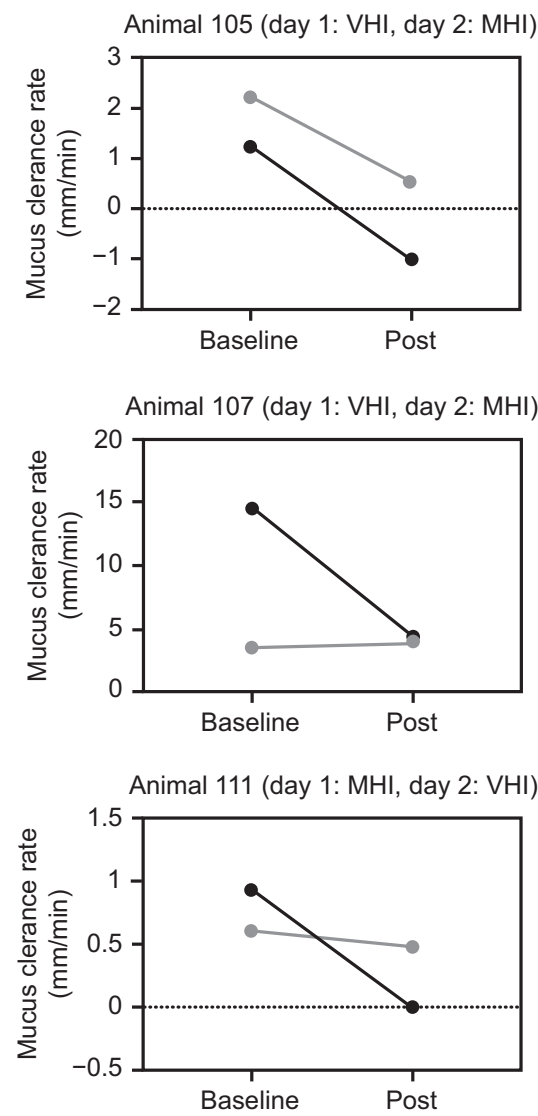
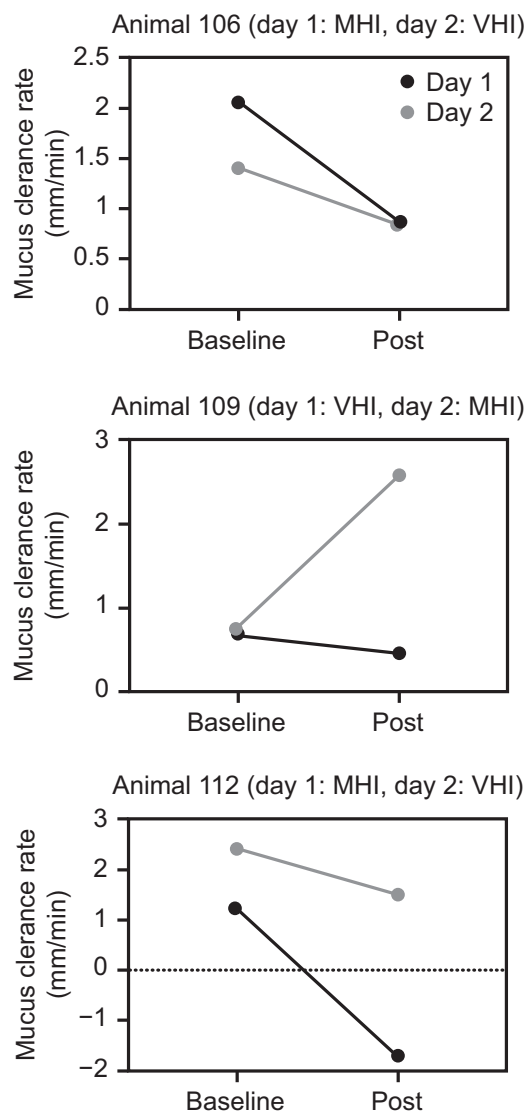

Fig. 6. Mucus clearance rate per intervention and day of assessment. Mucus clearance rate did not differ among study intervention $(P=.09)$ and study days $(P=.75)$. At baseline, mucus clearance rate was faster in 3 animals and slower or similar in the 3 remaining animals.

improvements in pulmonary mechanics and surrogate measures of mucus clearance, ${ }^{17}$ particularly when it was performed with the Mapleson-C circuit ${ }^{18}$ and combined with the Trendelenburg position. ${ }^{19}$ Ventilator hyperinflation has been proposed recently as an alternative technique to prevent several of the potential drawbacks of manual hyperinflation, such as ventilatory disconnection and tidal hyperinflation heterogeneity. ${ }^{12}$ Lemes et $\mathrm{al}^{20}$ evaluated the effects of 30-min ventilator hyperinflation, up to $40 \mathrm{~cm} \mathrm{H}_{2} \mathrm{O}$, in subjects with pulmonary infection and reported an increased amount of collected mucus. Similar benefits were noted with either technique in a meta-analysis. ${ }^{14}$ Yet, during ventilator hyperinflation, disconnection from mechanical ventilation is not necessary, and $\mathrm{V}_{\mathrm{T}}$ and airway pressures are strictly monitored by the ventilator. In this study, ventilator hyperinflation achieved consistent ventilatory end points, as planned for by the protocol. Despite these findings, it is important to highlight that manual hyperinflation remains the most commonly used hyperinflation technique in clinical settings. This could be related to the fact that ventilator hyperinflation is a relatively new method of lung hyperinflation, and health care providers may not be appropriately trained in adjusting the ventilator settings to safely deliver the intervention.
The applied interventions efficiently improved both the bias between PEF and mean inspiratory flow (by $60 \mathrm{~L} / \mathrm{min}$ ) and the bias between mean expiratory flow from the beginning of expiration to zero-flow and mean inspiratory flow (by 16-21 L/min). Nevertheless, in our model of pneumonia the median mucus clearance rate ranged from 0.65 to 1.31 . These rates are similar to previous studies in healthy animals 5 but do not indicate any beneficial effect of either type of hyperinflation on mucus clearance. It is difficult to explain these negative findings, particularly in view of several prior bench and animal model reports that showed enhanced mucus clearance when the expiratory flow overcame the inspiratory flow. $5,8,21$ Several features of our settings should be considered to better characterize these findings. First, lung hyperinflation theoretically resembles a cough burst. Efficient cough includes lung hyperinflation, swift glottic closure, and forced expiration. ${ }^{22}$ Conversely, during both manual hyperinflation and ventilator hyperinflation, the endotracheal tube prevents full closure of the glottis, thus reducing the peak expiratory flow. ${ }^{23}$ Second, in comparison to standard mechanical ventilation, manual hyperinflation and ventilator hyperinflation increased the inspiratory time 4-fold; thus, the prolonged interaction of the inspiratory air flow 
Manual vs Ventilator Hyperinflation in an Animal Model

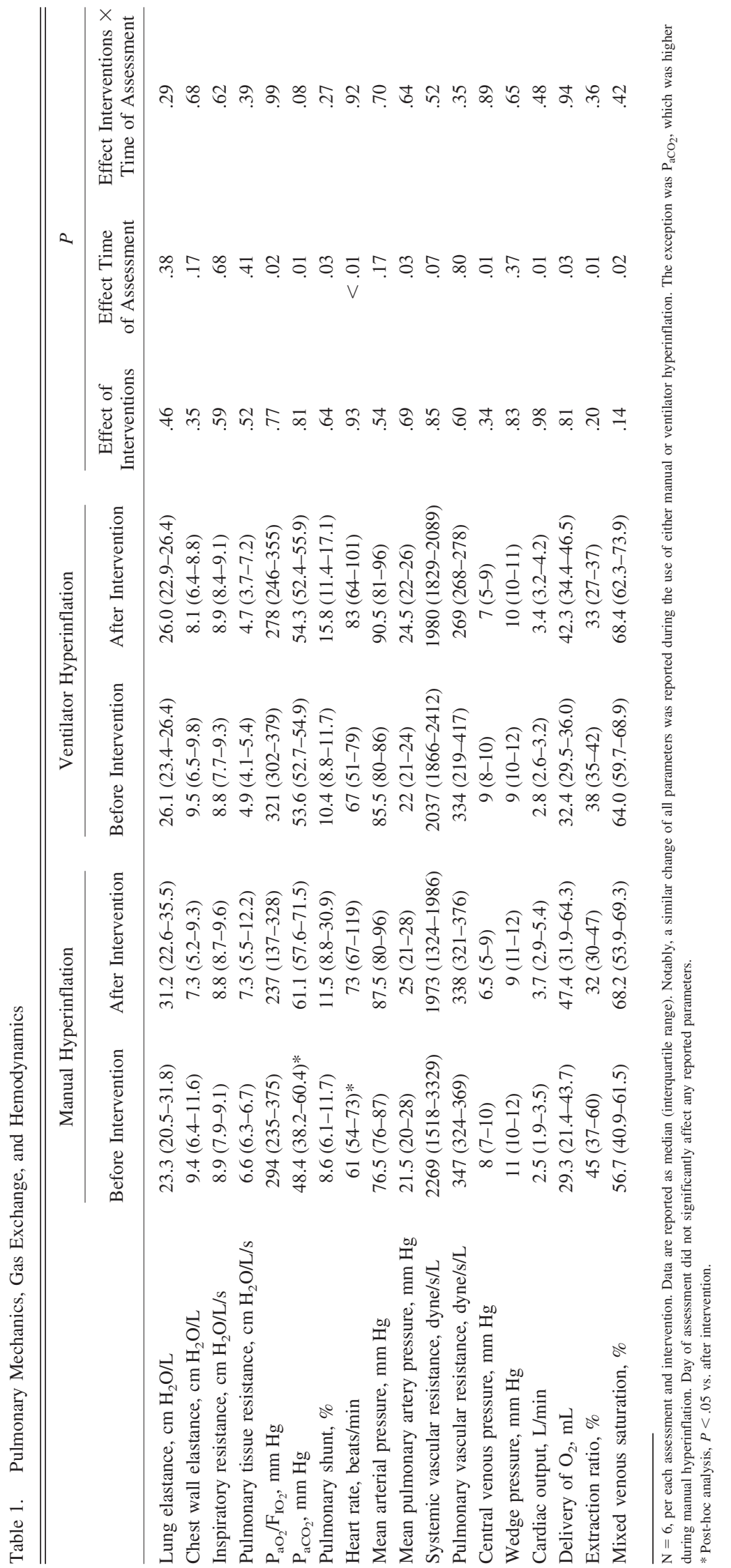


with mucus could have slowed the clearance rate rather than promoting it. Third, tracheal suctioning was performed $1 \mathrm{~h}$ prior to initiation of the protocol for baseline normalization of retained secretions. Previously, Landa et $\mathrm{al}^{24}$ showed negative effects of suctioning on mucus clearance, but only when prolonged aspiration of up to $24 \mathrm{~h}$ was applied. Fourth, our previous studies ${ }^{25}$ in animals, in a model of semi-recumbent position and on invasive mechanical ventilation, demonstrated that brief and strong rib-cage compressions, synchronized with the early expiratory phase, improved outward clearance of mucus. Thus, if not contraindicated, rib-cage compressions could be applied following hyperinflation as a suitable alternative to enhance airway clearance. Another feasible option, as reported by Berney et $\mathrm{al}^{19}$ and previous laboratory studies, ${ }^{6}$ would be to position the patient in a slight Trendelenburg position to enhance gravity-driven mucus movement. It should be emphasized that, in our model, animals were kept in a prone position rather than supine like in humans. Indeed, pigs are quadrupeds and commonly develop extensive atelectasis and respiratory derangement when maintained in the supine position for prolonged periods. As previously shown, ${ }^{26}$ in the prone position the pig trachea is ventrally tilted, which could theoretically favor gravitydriven mucus clearance. In contrast, in the supine position, tracheal orientation both in pigs and humans has an oblique orientation toward the dorsal region, which potentially thwarts mucus clearance. Hence, our negative results should be considered in light of these specific tracheal orientations and potential inter-species dissimilarities. Finally, we measured mucus clearance at the most dependent midtracheal regions. In this area, as we previously demonstrated, $5,6,27$ movement of retained mucus is mainly driven by gravitational force and flows. Thus, during baseline assessments, gravity might have played the most important role on mucus displacement, particularly because animals were positioned fully horizontal.

As for the effects of hyperinflation on gas exchange and pulmonary mechanics, manual hyperinflation improved pulmonary compliance in previous studies, ${ }^{17,28-30}$ but the effects on arterial oxygenation were inconsistent, ${ }^{17}$ particularly in subjects with lung injury. ${ }^{31}$ In addition, manual hyperinflation was often associated with significant decrease in cardiac output, ${ }^{32,33}$ changes in heart rate, ${ }^{31,34}$ and, sometimes, an increase in systemic vascular resistance ${ }^{32}$ and end-tidal carbon dioxide. ${ }^{34}$ Overall these deleterious effects had limited clinical relevance, specifically in patients with shock or lung injury. In our study, gas exchange and hemodynamics (ie, heart rate and central venous pressure) were altered equally by manual hyperinflation and ventilator hyperinflation. Nevertheless, it should be emphasized that pulmonary and hemodynamic parameters were assessed 15 min after completion of the intervention, potentially lacking temporal association. In particular, because
PEEP was not increased following application of the maneuver, the potential gain in pulmonary recruitment could have been lost during the waiting period.

This study has some limitations that should be addressed. First, our laboratory findings should be judiciously extrapolated into clinical scenarios due to the limited number of studied animals and inherent differences between our porcine model (eg, deep sedation and paralysis with absence of cough or any expiratory muscle activity) with the ICU patient. Yet this is the first report to objectively quantify mucus clearance during lung hyperinflation, adding novel insightful information to this field of investigation. Second, animals were kept in a prone horizontal position, rather than in a model of the semi-recumbent position, as in our previous reports. ${ }^{6}$ Thus, in comparison with patients, who are commonly positioned in the semi-recumbent position, we might have overestimated the effects of hyperinflation on mucus clearance. Moreover, the level of lung hyperinflation might have been thwarted by the abdominal viscera forcing against the diaphragm. Third, we tested the interventions in a model of severe pneumonia and, differently than in clinical settings, we did not increase PEEP after intervention. Thus, the lack of oxygenation improvement should be read in light of the applied methods and may not apply to different models of acute lung injury. Finally, a repeated-intervention study design was applied, and, although we randomized the interventions, potential carryover effect could have occurred.

\section{Conclusions}

Our findings reappraise the role of manual hyperinflation and ventilator hyperinflation as techniques to enhance mucus clearance and their utility during mechanical ventilation. Furthermore, in our porcine model of severe pneumonia, manual hyperinflation and ventilator hyperinflation exerted similar effects on gas exchange, pulmonary mechanics, and hemodynamics.

\section{ACKNOWLEDGMENTS}

We thank the nurses of the Pulmonary Critical Care Unit, Hospital Clinic, Barcelona, for their invaluable and consistent support.

\section{REFERENCES}

1. Hedenstierna G, Tokics L, Strandberg A, Lundquist H, Brismar B. Correlation of gas exchange impairment to development of atelectasis during anaesthesia and muscle paralysis. Acta Anaesthesiol Scand 1986;30(2):183-191.

2. Tokics L, Hedenstierna G, Strandberg A, Brismar B, Lundquist H. Lung collapse and gas exchange during general anesthesia: effects of spontaneous breathing, muscle paralysis, and positive end-expiratory pressure. Anesthesiology 1987;66(2):157-167.

3. Sackner MA, Hirsch J, Epstein S. Effect of cuffed endotracheal tubes on tracheal mucous velocity. Chest 1975;68(6):774-777. 


\section{Manual vs Ventilator Hyperinflation in an Animal Model}

4. Konrad F, Schreiber T, Brecht-Kraus D, Georgieff M. Mucociliary transport in ICU patients. Chest 1994;105(1):237-421.

5. Li Bassi G, Saucedo L, Marti J-D, Rigol M, Esperatti M, Luque N, et al. Effects of duty cycle and positive end-expiratory pressure on mucus clearance during mechanical ventilation. Crit Care Med 2012; 40(3):895-902.

6. Li Bassi G, Marti JD, Saucedo L, Rigol M, Roca I, Cabanas M, et al. Gravity predominates over ventilatory pattern in the prevention of ventilator-associated pneumonia. Crit Care Med 2014;42(9):e620-627.

7. Kim CS, Iglesias AJ, Sackner MA. Mucus clearance by two-phase gas-liquid flow mechanism: asymmetric periodic flow model. J Appl Physiol 1987;62(3):959-971.

8. Volpe MS, Adams AB, Amato MBP, Marini JJ. Ventilation patterns influence airway secretion movement. Respir Care 2008;53(10):12871294.

9. Tweed WA, Phua WT, Chong KY, Lim E, Lee TL. Tidal volume, lung hyperinflation and arterial oxygenation during general anaesthesia. Anaesth Intensive Care 1993;21(6):806-810.

10. Clement AJ, Hübsch SK. Chest physiotherapy by the "bag squeezing" method: a guide to technique. Physiotherapy 1968;54(10):355-359.

11. Stone KS. Ventilator versus manual resuscitation bag as the method for delivering hyperoxygenation before endotracheal suctioning. AACN Clin Issues Crit Care Nurs 1990;1(2):289-299.

12. Paulus F, Binnekade JM, Middelhoek P, Vroom MB, Schuitz MJ. Guideline implementation powered by feedback and education improves manual hyperinflation performance. Nurs Crit Care 2014; 21(1):36-43

13. Berney S, Denehy L. A comparison of the effects of manual and ventilator hyperinflation on static lung compliance and sputum production in intubated and ventilated intensive care patients. Physiother Res Int 2002;7(2):100-108.

14. Anderson A, Alexanders J, Sinani C, Hayes S, Fogarty M. Effects of ventilator vs manual hyperinflation in adults receiving mechanical ventilation: a systematic review of randomised clinical trials. Physiotherapy 2015;101(2):103-110.

15. Li Bassi G, Marti JD, Xiol EA, Comaru T, De Rosa F, Rigol M, et al. The effects of direct hemoperfusion using a polymyxin B-immobilized column in a pig model of severe Pseudomonas aeruginosa pneumonia. Ann Intensive Care 2016;6(1):58

16. Luna CM, Baquero S, Gando S, Patrón JR, Morato JG, Sibila O, et al. Experimental severe Pseudomonas aeruginosa pneumonia and antibiotic therapy in piglets receiving mechanical ventilation. Chest 2007;132(2):523-531.

17. Paulus F, Binnekade JM, Vroom MB, Schultz MJ. Benefits and risks of manual hyperinflation in intubated and mechanically ventilated intensive care unit patients: a systematic review. Crit Care 2012; 16(4):R145

18. Hodgson C, Ntoumenopoulos G, Dawson H, Paratz J. The Mapleson $\mathrm{C}$ circuit clears more secretions than the Laerdal circuit during manual hyperinflation in mechanically-ventilated patients: a randomised cross-over trial. Aust J Physiother 2007;53(1):33-38.

19. Berney S, Denehy L, Pretto J. Head-down tilt and manual hyperinflation enhance sputum clearance in patients who are intubated and ventilated. Aust J Physiother 2004;50(1):9-14.
20. Lemes DA, Zin WA, Guimarães FS. Hyperinflation using pressure support ventilation improves secretion clearance and respiratory mechanics in ventilated patients with pulmonary infection: a randomised crossover trial. Aust J Physiother 2009;55(4):249-254.

21. Volpe MS, Naves JM, Ribeiro GG, Ruas G, Tucci MR. Effects of manual hyperinflation, clinical practice versus expert recommendation, on displacement of mucus simulant: a laboratory study. PLoS One 2018;13(2):e0191787.

22. McCool FD, Rosen MJ. Nonpharmacologic airway clearance therapies: ACCP evidence-based clinical practice guidelines. Chest 2006; 129(1 Suppl):250S-259S.

23. Gal TJ. Effects of endotracheal intubation on normal cough performance. Anesthesiology 1980;52(4):324-329.

24. Landa JF, Kwoka MA, Chapman GA, Brito M, Sackner MA Effects of suctioning on mucociliary transport. Chest 1980;77(2): 202-207.

25. Martí JD, Li Bassi G, Rigol M, Saucedo L, Ranzani OT, Esperatti M, et al. Effects of manual rib cage compressions on expiratory flow and mucus clearance during mechanical ventilation. Crit Care Med 2013; 41(3):850-856

26. Zanella A, Cressoni M, Epp M, Hoffmann V, Stylianou M, Kolobow T. Effects of tracheal orientation on development of ventilator-associated pneumonia: an experimental study. Intensive Care Med 2012; 38(4):677-685.

27. Li Bassi G, Zanella A, Cressoni M, Stylianou M, Kolobow T. Following tracheal intubation, mucus flow is reversed in the semirecumbent position: possible role in the pathogenesis of ventilatorassociated pneumonia. Crit Care Med 2008;36(2):518-525.

28. Blattner C, Guaragna JC, Saadi E. Oxygenation and static compliance is improved immediately after early manual hyperinflation following myocardial revascularisation: a randomised controlled trial. Aust J Physiother 2008;54(3):173-178.

29. Choi JS-P, Jones AY-M. Effects of manual hyperinflation and suctioning in respiratory mechanics in mechanically ventilated patients with ventilator-associated pneumonia. Aust J Physiother 2005;51(1): 25-30

30. Paratz J, Lipman J, McAuliffe M. Effect of manual hyperinflation on hemodynamics, gas exchange, and respiratory mechanics in ventilated patients. J Intensive Care Med 2002;17(6):317-324.

31. Barker M, Adams S. An evaluation of a single chest physiotherapy treatment on mechanically ventilated patients with acute lung injury. Physiother Res Int 2002;7(3):157-169.

32. Paratz J, Lipman J. Manual hyperinflation causes norepinephrine release. Heart Lung 2006;35(4):262-268.

33. Singer M, Vermaat J, Hall G, Latter G, Patel M. Hemodynamic effects of manual hyperinflation in critically ill mechanically ventilated patients. Chest 1994;106(4):1182-1187.

34. Paulus F, Binnekade JM, Vermeulen M, Vroom MB, Schultz MJ. Manual hyperinflation is associated with a low rate of adverse events when performed by experienced and trained nurses in stable critically ill patients-a prospective observational study. Minerva Anestesiol 2010;76(12):1036-1042.

This article is approved for Continuing Respiratory Care Education credit. For information and to obtain your CRCE

(free to AARC members) visit

\section{www.rcjournal.com}

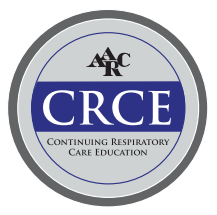

